\title{
Treinamento ambiental e competências individuais para sustentabilidade ambiental: um estudo em três empresas químicas brasileiras
}

\section{Environmental training and individual skills for environmental sustainability: a study of three Brazilian chemical companies}

\author{
Marco Antonio Batista da Silva ${ }^{1 \mathrm{i}}$ \\ Orcid: https://orcid.org/0000-0003-4616-4038
}

Priscila Rezende da Costa ${ }^{2 i i}$

Orcid: https://orcid.org/0000-0002-7012-0679

\section{Cláudia Terezinha Kniess ${ }^{3 i i i}$}

Orcid: https://orcid.org/0000-0002-1961-2037

\begin{abstract}
Resumo
O objetivo geral deste trabalho é analisar como o treinamento ambiental pode contribuir para o desenvolvimento de competências individuais associadas à dimensão ambiental da sustentabilidade em grandes empresas do setor químico brasileiro. Tal estudo justifica-se pela necessidade de se preencher gaps teóricos e metodológicos sobre o papel do processo de treinamento ambiental, visando à dimensão ambiental da sustentabilidade no contexto das empresas do setor químico brasileiro. $\mathrm{O}$ tema foi tratado utilizando-se abordagem de pesquisa qualitativa com estudo de caso múltiplo baseada em triangulação de fontes de evidências. Os resultados apontam para a confirmação de que a sistematização do processo de treinamento ambiental pode potencializar o desenvolvimento de competências individuais, essenciais à sustentabilidade das empresas do setor químico brasileiro, considerando-se que o processo de treinamento ambiental é voltado para estimular e desenvolver as competências individuais alinhadas à estratégia organizacional, a partir dos gaps de competência identificados.

Palavras-chave: treinamento ambiental; desenvolvimento de competências; sustentabilidade. setor químico.
\end{abstract}

\begin{abstract}
This paper aims to analyze how the environmental training process can contribute to the development of individual competencies associated with the environmental dimension of sustainability in large companies in the Brazilian chemical sector. The need to fill theoretical and methodological gaps on the role of the environmental training process, targeted at the environmental dimension of sustainability in the context of companies in the Brazilian chemical sector justifies this study. A qualitative research approach with multiple case studies based on triangulation of evidence sources addressed the theme. The results confirmed that the systematization of the environmental training process can potentiate the development of individual competencies, essential to the sustainability of the companies of the Brazilian chemical sector, considering that the environmental training process is directed at stimulating and developing the competencies aligned with the organizational strategy, based on identified competence gaps.

Keywords: environmental training; skills development, sustainability, chemical sector.
\end{abstract}

\footnotetext{
${ }^{1}$ Instituto Federal de Educação, Ciência e Tecnologia do Sul de Minas -IFSULDEMIA, Minas Gerais, Brasil. E-mail: prof.marcoabs@gmail.com

${ }^{2}$ Universidade Nove de Julho -Uninove, Brasil. E-mail: priscilarezende@yahoo.com.br

${ }^{3}$ Universidade Federal de São Paulo (UNIFESP), Universidade São Judas Tadeu (USJT) e Universidade de Taubaté (UNITAU), Brasil. Email:kniesscl@yahoo.com.br
} 


\section{INTRODUÇÃO}

O interesse da sociedade, dos governos e das organizações sobre o tema sustentabilidade é crescente. Inserida nesse contexto, indústria química no Brasil desempenha um papel importante, ocupando em 2018 o terceiro lugar no desenvolvimento do Produto Interno Bruto (PIB) industrial brasileiro e, também em 2018, a sexta colocação em termos de faturamento líquido do mundo (ABIQUM, 2020). Apesar desse setor desenvolver produtos essenciais para a humanidade, a produção química tem gerado discussões no que diz respeito ao seu papel em relação à sustentabilidade, principalmente pelos inconvenientes causados, como formação de subprodutos tóxicos, contaminação do meio ambiente, riscos apresentados por produtos e processos que geram volumes de efluentes tóxicos.

Soto (2012) afirma que, apesar da melhoria nos números quanto à redução na taxa de acidentes com afastamento, de emissões e de consumo de água, o volume de produção cresceu mais que a melhoria alcançada, ou seja, houve aumento nos impactos ambientais e sociais, em termos de valores absolutos, apresentando alguns desafios e dilemas como específicos da indústria química, como: periculosidade dos produtos químicos, mudanças climáticas, gases de efeito estufa e energia, consumo de água, uso de matéria-prima não renovável, pós-consumo e fortalecimento dos relacionamentos. Diante desses desafios, a adoção da sustentabilidade pelas indústrias químicas pode ser uma grande oportunidade para o desenvolvimento do setor (SOTO, 2012).

Nesse contexto, o treinamento ambiental apresenta-se como uma dessas dimensões organizacionais com papel importante para as empresas que "abraçam a filosofia da sustentabilidade" (JACKSON; SCHULER; JIANG, 2014, p. 40; JABBOUR; SANTOS, 2008b).

Dentre as lacunas nos estudos sobre o treinamento ambiental, Jabbour (2013) destaca que as fases do processo de treinamento não foram exploradas nos estudos realizados. Sendo assim, o autor destaca a importância do desenvolvimento de estudos que busquem contribuir para o conhecimento das fases do processo de treinamento ambiental.

A partir dos gaps apresentados no que tange à temática treinamento ambiental, enuncia-se como objetivo geral analisar como o treinamento ambiental pode contribuir para o desenvolvimento de competências individuais associadas à dimensão ambiental da sustentabilidade em empresas do setor químico brasileiro. Para contribuir para a consecução desse propósito, foram definidos os seguintes objetivos específicos: a) caracterizar o processo de treinamento ambiental desenvolvido pelas empresas químicas estudadas e b) identificar nessas empresas as competências individuais consideradas relevantes à sustentabilidade ambiental.

\section{REFERENCIAL TEÓRICO}

\subsection{Treinamento Ambiental}

O treinamento ambiental é definido como um processo de treinamento no trabalho e de educação continuada que busca atingir os objetivos e propósitos da gestão ambiental corporativa, habilitando todos os níveis organizacionais a integrar o desempenho da organização às questões ambientais (TEIXEIRA, et al., 2016). Tal escolha justifica-se pelo fato de o conceito destacar a dimensão estratégica do treinamento ambiental, pois não é caracterizado somente como uma dimensão técnica, abrangendo aqueles que atuam em cargos da gestão ambiental, mas estende-se a todos os níveis organizacionais. Também não está associado somente a uma ação instrucional, mas a um processo contínuo de educação, tendo como objetivo o desempenho organizacional na dimensão ambiental.

Dermol e Cater (2013) definiram treinamento como um processo de atualização, revisão e sistematização de 
conhecimentos, habilidades, hábitos e competências dos empregados, visando não somente situações específicas atribuídas ao trabalho atual, mas também buscando antecipar e satisfazer necessidades futuras da organização, com base em necessidades reais de empregados e organizações, tendo em vista a identificação de potenciais mudanças ambientais. Tal pensamento está alinhado à caracterização do treinamento ambiental em seus três subprocessos: análise das necessidades (diagnóstico); desenvolvimento (planejamento e execução); e avaliação.

\subsubsection{Análise das Necessidades de Treinamento}

Análise das necessidades de treinamento abrange tanto descrições de lacunas de conhecimento, habilidades e atitudes, que são componentes básicos das competências voltadas para o trabalho, quanto as lacunas nas competências relacionadas às diversas esferas requeridas pela sociedade (ABBAD; MOURÃO, 2012; SILVA; MENEZES, 2012).

A análise do gap entre as competências que as pessoas na organização possuem e aquelas necessárias para se alcançarem os objetivos organizacionais deve ser a rota a ser seguida pela análise das necessidades de treinamento, considerando três níveis de análise: organizacional, envolvendo as necessidades oriundas da missão e das estratégias da organização; operacional, que analisa as exigências das competências que contribuem para o alcance dos objetivos de cada trabalho; e nível individual que avalia o gap do desempenho de cada indivíduo de acordo com padrões estabelecidos, focado no processo de decidir quem $e$ o que deve ser treinado (NARASHIMHAN; RAMANARAYANAN, 2014; SALAS; CANNON-BOWERS, 2001).

Arshad, Yusof, Mahmood, Ahmed e Akthar (2015), descreveram as duas abordagens presentes no desenvolvimento da avaliação das necessidades de treinamento: a abordagem reativa e a proativa. Em uma perspectiva reativa, a avaliação das necessidades pauta-se na diferença entre o desempenho no trabalho esperado e realizado, não tendo como foco a ligação entre as competências necessárias aos objetivos estratégicos da organização. $\mathrm{Na}$ abordagem proativa, há a ampliação da área de análise, buscando-se avaliar o ambiente de negócios em que a alta gestão é inserida na avaliação, visando a determinação de competências necessárias às mudanças importantes que ocorrem na organização, a fim de responder às exigências fundamentais para a competitividade dessa organização.

\subsubsection{Desenvolvimento do Treinamento}

As estratégias para desenvolvimento de ações de treinamento podem ser definidas como ferramentas, conteúdos e métodos que devem ser combinados para se atingir os objetivos propostos pelo programa de treinamento, tendo como base quatro princípios básicos: apresentar informações ou conceitos relevantes a serem aprendidos; demonstrar os conhecimentos, habilidades e atitudes que devem ser desenvolvidos; criar oportunidade para aplicação prática das habilidades e, por fim, fornecer feedback aos treinados durante e depois das práticas (SALAS; CANNON-BOWERS, 2001).

O desenvolvimento das estratégias de treinamento insere o planejamento $\mathrm{e} a$ execução de ações que consistem em "redação dos objetivos instrucionais, escolha da modalidade de entrega da instrução, estabelecimento da sequência dos objetivos e conteúdo, seleção ou criação dos procedimentos instrucionais, definição de critérios de avaliação de aprendizagem e teste do desenho instrucional" (SILVA; MOURA; ZANELLI, 2005, p. 232).

Dentre as etapas apresentadas por Abbad, Zerbini, Carvalho e Meneses (2006), ao tratarem do desenho instrucional que compõem o processo de um planejamento instrucional, na figura 1 pode-se verificar as etapas que serão analisadas neste trabalho. 
Figura 1 - Etapas do desenvolvimento das estratégias de treinamento.

\begin{tabular}{|c|c|}
\hline Etapas & Caracterização \\
\hline $\begin{array}{l}\text { Escolha da } \\
\text { modalidade }\end{array}$ & $\begin{array}{l}\text { Devem-se considerar as características dos que receberão as ações educacionais de } \\
\text { treinamento, tais como: perfil demográfico, profissional e funcional; as discrepâncias de } \\
\text { competências dos aprendizes; complexidade e natureza dos objetivos instrucionais; e recursos } \\
\text { financeiros, tecnológicos e materiais disponíveis. As modalidades podem ser: presencial, a } \\
\text { distância ou semipresencial. }\end{array}$ \\
\hline $\begin{array}{l}\text { Estabelecimento da } \\
\text { Sequência }\end{array}$ & $\begin{array}{l}\text { Partir de um domínio menos complexo ao mais complexo, com base na sequência dos } \\
\text { requisitos necessários a serem aprendidos. }\end{array}$ \\
\hline $\begin{array}{l}\text { Criação/Escolha dos } \\
\text { procedimentos }\end{array}$ & $\begin{array}{l}\text { Os procedimentos instrucionais são dependentes dos meios ou ferramentas e de condições } \\
\text { ambientais específicas. } \\
\text { Os procedimentos devem adequar-se aos objetivos e às características da clientela. } \\
\text { Os recursos a serem utilizados devem ter como base as competências a serem desenvolvidas e } \\
\text { a modalidade a ser utilizada. }\end{array}$ \\
\hline
\end{tabular}

Fonte: Adaptado de Abbad, Zerbini, Carvalho e Meneses (2006).

\subsection{3 - Avaliação do Treinamento}

A avaliação do que ocorre após o treinamento, com desenvolvimento de métodos e processos que avaliem $\mathrm{o}$ treinamento e os eventos que garantem a transferência e aplicação dos novos conhecimentos, habilidades e atitudes, é tão importante quanto o que acontece antes e durante o treinamento. No entanto, há dificuldade de realização dessas atividades, pois se trata de um trabalho intenso, caro, político, difícil de realizar e que muitas vezes não apresenta notícias boas (SALAS; CANNON-BOWERS, 2001). Na busca por contribuir com esse processo de avaliação de treinamentos, alguns autores desenvolveram modelos de avaliação de treinamento, bem como analisaram a sua avaliação, considerando a transferência do treinamento entendida como o grau em que os indivíduos treinados aplicam e mantêm, por um período, os conhecimentos, habilidades e atitudes adquiridos no treinamento, ao seu contexto de trabalho (BALDWIN; FORD, 1988).

Os modelos de avaliação de treinamento que fundamentam este trabalho apresentam a complexidade do processo de avaliação. Diversos fatores influenciam esse processo e podem comprometer seu resultado. Tanto elementos do próprio treinamento quanto externos a ele caracterizam a complexidade da avaliação do treinamento. Diante dos estudos apresentados no que se refere à avaliação de treinamento, na figura 2 será apresentada uma síntese da base teórica com seus autores.

Figura 2 - Síntese base teórica de avaliação de treinamento.

\begin{tabular}{|c|c|c|c|}
\hline Dimensão & Característica & Descrição & Autores \\
\hline \multirow{4}{*}{ Transferência } & $\begin{array}{l}\text { Horizontal ou } \\
\text { intranível }\end{array}$ & $\begin{array}{l}\text { Disseminação da aprendizagem em um mesmo } \\
\text { nível, seja individual, grupal ou organizacional }\end{array}$ & \multirow{2}{*}{$\begin{array}{l}\text { Abbad, Pilati e Pantoja } \\
(2003)\end{array}$} \\
\hline & $\begin{array}{l}\text { Vertical ou } \\
\text { internível }\end{array}$ & $\begin{array}{l}\text { Diz respeito à transmissão de habilidades adquiridas } \\
\text { ou desenvolvidas de um nível para o outro, tanto no } \\
\text { sentido top-down como no sentido bottom-up. }\end{array}$ & \\
\hline & Generalização & $\begin{array}{l}\text { Transferência para o ambiente de trabalho, do que } \\
\text { foi aprendido no treinamento. }\end{array}$ & \multirow[t]{2}{*}{ Baldwin e Ford (1988) } \\
\hline & Manutenção & $\begin{array}{l}\text { Aplicação no trabalho do que foi aprendido, por um } \\
\text { longo período. }\end{array}$ & \\
\hline \multirow[t]{2}{*}{$\begin{array}{l}\text { Nível de } \\
\text { Avaliação }\end{array}$} & Reação & $\begin{array}{l}\text { Medida que indica a satisfação do cliente com o } \\
\text { treinamento envolvendo diversos critérios como, por } \\
\text { exemplo, conteúdo, recursos empregados, material } \\
\text { utilizado, o treinador, o ambiente. }\end{array}$ & $\begin{array}{l}\text { Kirkpatrick (2010); } \\
\text { Borges-Andrade (2006); }\end{array}$ \\
\hline & Aprendizagem & $\begin{array}{l}\text { Busca identificar conhecimentos adquiridos, } \\
\text { habilidades desenvolvidas ou aprimoradas e atitudes } \\
\text { modificadas. A avaliação da aprendizagem é um nível } \\
\text { mais difícil que a avaliação da reação. }\end{array}$ & $\begin{array}{l}\text { Kirkpatrick (2010) Holton } \\
(1996) \text {; Baldwin e Ford } \\
(1988) \text {; Borges-Andrade } \\
(2006) \text {. }\end{array}$ \\
\hline
\end{tabular}




\begin{tabular}{|c|c|c|c|}
\hline \multirow{3}{*}{$\begin{array}{l}\text { Nível de } \\
\text { Avaliação }\end{array}$} & Comportamento & $\begin{array}{l}\text { Diz respeito à extensão em que os participantes } \\
\text { mudam seu comportamento no trabalho em virtude } \\
\text { do treinamento, também chamado de transferência } \\
\text { do treinamento, tal mudança requer a consideração } \\
\text { de muitos fatores e uma abordagem mais científica. }\end{array}$ & $\begin{array}{l}\text { Kirkpatrick (2010); } \\
\text { Borges-Andrade (2006). }\end{array}$ \\
\hline & $\begin{array}{l}\text { Desempenho } \\
\text { individual }\end{array}$ & $\begin{array}{l}\text { Os resultados de aprendizagem conseguidos pela } \\
\text { intervenção da área de gestão de pessoas mudarão o } \\
\text { desempenho do indivíduo e, em consequência, } \\
\text { resultará em um nível melhor dos resultados } \\
\text { organizacionais. }\end{array}$ & Holton (1996) \\
\hline & Resultado & $\begin{array}{l}\text { Inclui crescimento nas vendas, melhoria na qualidade } \\
\text { dos produtos e/ou serviços, aumento da } \\
\text { produtividade, aumento dos lucros, redução de } \\
\text { acidentes de trabalho, da rotatividade e o absenteísmo } \\
\text { dos funcionários, redução na taxa de produtos } \\
\text { rejeitados, melhora na comunicação interpessoal e } \\
\text { nas relações humanas, melhora na administração do } \\
\text { tempo. }\end{array}$ & $\begin{array}{l}\text { Kirkpatrick (2010); Holton } \\
(1996) \text {; Borges-Andrade } \\
(2006)\end{array}$ \\
\hline
\end{tabular}

Fonte: Adaptado dos autores citados.

\subsection{Sustentabilidade Ambiental}

Há um debate bastante rico no meio acadêmico, com uma diversidade teórica sobre o conceito de sustentabilidade. No entanto, um dos conceitos mais adotados foi o apresentado no relatório de Brundtland (1987): que a humanidade tenha capacidade de atender suas necessidades do presente, sem comprometer a capacidade de as gerações futuras satisfazerem suas próprias necessidades (CLARO; CLARO; AMÂNCIO, 2008).

Um ponto comum na discussão teórica sobre sustentabilidade é que ela é composta de três dimensões que se relacionam: econômica, ambiental e social. No que tange à dimensão ambiental da sustentabilidade, os princípios são fazer uso racional dos recursos naturais; tratar $\mathrm{e}$ disponibilizar adequadamente os resíduos gerados (SEVERO; DORION; GUIMARÃES, 2017). A adoção de práticas ambientais contribui para a minimização de danos ao meio ambiente por meio do planejamento da gestão ambiental pelas organizações (SEVERO; DE GUIMARÃES; MORAIS, 2020). O desenvolvimento ou modificação de produtos, serviços, processos sem descuidar das demandas ambientais contribui para que as empresas adquiram vantagem competitiva (SANTOS et al., 2019).

A sustentabilidade ambiental no âmbito organizacional é definida como uma série de políticas conectadas com atividades e tomadas de decisões de forma que garanta a existência da organização e maximize os impactos positivos à sociedade, entendendo o capital natural de duas formas principais: capital natural crítico, aquele que é essencial para a vida e integridade do ecossistema; e capital natural renovável que pode ser recuperado ou substituído. O pilar ambiental da sustentabilidade é caracterizado pela priorização da prevenção do impacto ambiental gerado pela organização; pela busca de conformidade às normas governamentais; pelo desenvolvimento de iniciativas de reciclagem, de uso eficiente de energia, de água e de recursos naturais; pela minimização das práticas que possam afetar o acesso das gerações futuras aos recursos; bem como por se levar em consideração o impacto do ciclo de vida dos produtos. (ELKINGTON, 2001; MUNCK; BORIMDE-SOUZA, 2012). Dessa forma, os aspectos do desempenho da sustentabilidade ambiental relacionam-se com uso de materiais; consumo de energia; utilização da água; biodiversidade; efluentes e resíduos; emissões de poluentes; programas de reciclagem; mecanismos de reclamações sobre impacto ambiental; participação em programa ambiental voluntário; ser membro de grupo ambiental; avaliação de fornecedor com foco 
ambiental; ter um sistema de gestão ambiental; metas mensuráveis para treinamento dos funcionários (ELKINGTON, 2001; DEMAJOROVIC, 2003; COLLINS et al., 2006; GRI, 2013).

A dimensão ambiental da sustentabilidade, que é o foco de estudo deste trabalho, em interação com as outras duas dimensões desenvolve a ecoeficiência e a justiça ambiental. A lógica ecoeficiente envolve os pilares econômico e ambiental, sendo caracterizada pelo fornecimento, a preços competitivos, de produtos e serviços que satisfaçam as necessidades humanas, reduzindo os impactos ecológicos e a intensidade de recursos durante o ciclo de vida a um nível próximo do suportável, sem comprometer as gerações futuras. Busca prosperidade econômica por meio da utilização mais eficiente dos recursos naturais gerando menos emissões nocivas ao ambiente, contribuindo para a sustentabilidade econômica e ambiental. A estrutura de justiça ambiental surge a partir da relação balanceada entre os pilares ambiental e social e está associada à equidade intra e intergerações, que considera tanto a equidade entre as pessoas vivas quanto entre $o$ equilíbrio das vantagens entre diferentes gerações, mesmo aquelas que ainda estão por nascer (ELKINGTON, 2001; MUNCK e BORIMDE-SOUZA, 2012).

\subsection{Competências Individuais alinhadas à Sustentabilidade Ambiental}

\footnotetext{
Wiek, Withycombe e Redman (2011)

definiram competência para a sustentabilidade como uma funcionalidade relacionada a conhecimentos complexos, habilidades e atitudes que possibilitam o sucesso no desenvolvimento de tarefas e
}

soluções de problemas que dizem respeito aos desafios e oportunidades da sustentabilidade do mundo real.

Lambrechts, Mulà, Ceulemans, Molderez e Gaeremynck (2012) referiramse às competências chave do indivíduo como aquelas habilidades que são relevantes e úteis para se lidar com desafios de diferentes contextos da moderna sociedade. Dentre esses desafios encontra-se o desenvolvimento sustentável. Tais habilidades envolvem prérequisitos psicológicos que incluem aspectos cognitivos e não cognitivos.

Barth, Godemann, Rieckmann e Stoltenber (2007), apresentam duas abordagens as quais podem ser utilizadas para se entender a aquisição de competências: uma baseada no desenvolvimento de um profundo estágio de consciência por meio de um complexo processo cognitivo que considera a construção de modelos mentais; e outra, tendo como base a interiorização de valores, por meio de um processo de aprendizagem, produção, reprodução e comunicação de valores (Barth et al, 2007).

Ao se considerar todas as abordagens teóricas destacadas, para este trabalho, considerou-se, para sistematização das competências individuais alinhadas à sustentabilidade ambiental, o modelo estabelecido por Jabbour e Santos (2008a) em que o pilar ambiental é considerado na perspectiva da gestão ambiental, o pilar econômico na perspectiva da inovação e o pilar social associado à diversidade. A partir desse modelo, será apresentada uma síntese das principais competências mapeadas, no que tange ao desenvolvimento de competências individuais visando sustentabilidade ambiental. $\mathrm{Na}$ figura 3 apresentam-se as competências alinhadas à gestão ambiental. 
Figura 3 - Competências individuais alinhadas à gestão ambiental

\begin{tabular}{|c|c|c|}
\hline Dimensão & Competências & Autores \\
\hline $\begin{array}{l}\text { Gestão } \\
\text { Ambiental }\end{array}$ & $\begin{array}{l}\text { Orientação para saúde, segurança e meio ambiente; Habilidade de coletivamente } \\
\text { projetar e implementar intervenções em direção à sustentabilidade; Capacidade de } \\
\text { assumir responsabilidade por seu próprio trabalho; Capacidade de pensar e trabalhar } \\
\text { com visão sistêmica; Pensar e trabalhar com perspectiva orientada para o futuro; } \\
\text { Envolver-se pessoalmente ao desenvolvimento sustentável; Capacidade de integrar } \\
\text { negócio e problemas sociais e ambientais; Integrar os critérios tradicionais de } \\
\text { eficiência com eco e socioeficiência, bem como com efetividade; Lidar com } \\
\text { diferenças entre o foco e o grau do desejo de maximização dos resultados; Vivência em } \\
\text { comunhão com o meio ambiente; Consciência ambiental, social e econômica; } \\
\text { Eficiência. }\end{array}$ & $\begin{array}{l}\text { Van-Kleef e Roome (2007); } \\
\text { Wiek, et al. (2011); Roorda } \\
(2010) ; \text { Lambrechts, et al. } \\
(2012) ; \text { Barth, et al. (2007); } \\
\text { Eboli e Mancini (2012). }\end{array}$ \\
\hline
\end{tabular}

Fonte: Adaptado dos autores citados.

Ao se analisar as competências alinhadas à gestão ambiental, percebe-se que há um alinhamento à base conceitual do pilar ambiental da sustentabilidade, bem como ao modelo de integração da ecoeficiência, com interação do pilar ambiental e econômico, e da justiça ambiental que abrange a dimensão ambiental e social do TBL.

A partir do contexto teórico em que o processo de treinamento ambiental é caracterizado como um projeto voltado para desenvolver e estimular competências nas pessoas, alinhadas aos intentos estratégicos da organização para que as competências se viabilizem em um contexto no qual a sustentabilidade ambiental tem tido cada vez mais expressão na busca de desenvolvimento de vantagem competitiva para as organizações (FISCHER, 2002; MORAES; EBOLI, 2010; SALAS; CANNONBOWERS, 2001; AGUINIS; KRAIGER, 2009; SILVA; MENSES, 2012), enuncia-se a seguinte proposição de pesquisa: o treinamento ambiental pode potencializar o desenvolvimento de competências individuais essenciais à sustentabilidade das empresas do setor químico brasileiro.

Após uma síntese das principais abordagens teóricas nacionais $\mathrm{e}$ internacionais que discutem as fases do processo de treinamento, tanto em uma abrangência geral quanto para treinamento ambiental, passa-se a descrever os aspectos metodológicos da pesquisa.

\section{PROCEDIMENTOS METODOLÓGICOS}

Neste trabalho foi utilizada a abordagem de pesquisa qualitativa, oferecendo a possibilidade de estudo do fenômeno por diversas estratégias de pesquisa, bem como permitindo a flexibilidade na tomada de decisão com o avanço do processo de investigação (MASON, 1996).

A estratégia de pesquisa adotada foi o estudo de casos múltiplos, caracterizado por uma investigação empírica, em profundidade de um fenômeno contemporâneo (YIN, 2010), essencialmente útil quando se "deseja compreender os processos e interações sociais que se desenvolvem nas organizações" (GODOY, 2006, p. 127).

A indústria química no Brasil desempenha um papel importante, ocupando em 2018 o terceiro lugar no desenvolvimento do Produto Interno Bruto (PIB) industrial brasileiro e, em 2018, a sexta colocação em termos de faturamento líquido do mundo (ABIQUM, 2020). Alguns desafios e dilemas apresentam-se como específicos da indústria química, no que tange ao desenvolvimento de estratégia de sustentabilidade: periculosidade dos produtos químicos, mudanças climáticas, gases de efeito estufa e energia, consumo de água, uso de matéria-prima não renovável, pós-consumo e fortalecimento dos relacionamentos. Diante desses desafios, a adoção da sustentabilidade pelas indústrias químicas pode ser uma grande oportunidade para o desenvolvimento do setor (SOTO, 2012).

$\mathrm{Na}$ busca de alinhar-se à sustentabilidade, a indústria química tem priorizado o desenvolvimento de produtos, aplicações e processos para redução ou eliminação do uso e geração de substâncias tóxicas, potencializando os impactos econômicos, sociais e ambientais positivos e controlando e buscando minimizar os 
impactos negativos (PRADO, 2003; SOTO, 2012).

Para caracterizar a relevância dos casos escolhidos, contextualiza-se que no Brasil, em 1992, a Abiquim lançou o Programa de Atuação Responsável com objetivo de apoiar as empresas do setor químico a ela associada e em 2011 foi desenvolvida a ferramenta de implementação do Programa de Atuação Responsável que é o Sistema de Gestão e Atuação Responsável que busca prover as empresas de uma ferramenta que ajudará a desenvolver a cultura de melhoria contínua em: saúde, segurança e meio ambiente; na condução ética e transparente dos negócios; na proteção das pessoas e do meio ambiente; na integridade da propriedade; em canais de comunicação com stakeholders; na cadeia de valor e na valorização da imagem da indústria química e seus produtos (ABIQUIM, 2020). Diante desse contexto, os critérios de seleção dos casos foram: ser membro da ABIQUIM; ter o Sistema de Gestão do Programa Atuação Responsável e participarem com membro ativo da ABIQUIM, da Comissão de Meio Ambiente, que busca "promover o aperfeiçoamento da gestão ambiental das empresas químicas brasileiras associadas e da cadeia de valor, de forma a assegurar a sustentabilidade ambiental dos processos e produtos, bem como contribuir para a permanente melhoria da qualidade de vida da sociedade" (ABIQUIM, 2020). Buscando-se verificar a relevância na dimensão internacional dos casos, adotou-se como critério de escolha que também a empresa seja signatária do Pacto Global que é uma iniciativa desenvolvida pela ONU que tem como objetivo a mobilização da comunidade empresarial internacional para a adoção, em suas práticas de negócio, de valores fundamentais e internacionalmente aceitos, nas dimensões de direitos humanos, relações de trabalho, meio ambiente e combate à corrupção, pautadas em dez princípios estabelecidos pelo Pacto Global. Com base nesses critérios, as empresas estudadas foram: Braskem, Solvay e Beta (nome fictício, pois a empresa não autorizou sua identificação) (Figura 4).

Figura 4 - Caracterização empresarial das empresas pesquisadas.

\begin{tabular}{|c|c|c|c|}
\hline $\begin{array}{c}\text { Características } \\
\text { empresariais }\end{array}$ & Braskem & Solvay & Beta \\
\hline Natureza do capital & $\begin{array}{l}\text { Empresa de capital nacional aberto } \\
\text { pelo CDP Brasil (Carbon } \\
\text { Disclosure Project) na categoria } \\
\text { transparência. }\end{array}$ & $\begin{array}{l}\text { Empresa de capital estrangeiro } \\
\text { aberto }\end{array}$ & $\begin{array}{l}\text { Empresa de capital } \\
\text { estrangeiro aberto }\end{array}$ \\
\hline Porte & Grande & Grande & Grande \\
\hline Ano de fundação & $\begin{array}{l}\text { Criada em agosto de } 2002 \text { pela } \\
\text { integração de seis empresas da } \\
\text { Organização Odebrecht e do } \\
\text { Grupo Mariani. }\end{array}$ & 1863 por Ernest Solvay & Final do século XIX \\
\hline Localização & \begin{tabular}{|l|} 
Com sede administrativa em São \\
Paulo, a Braskem opera 29 unidades \\
industriais em São Paulo, Rio de \\
Janeiro, Rio Grande do Sul, Bahia e \\
Alagoas. No Brasil estão também \\
duas das suas três unidades do Centro \\
de Inovação e Tecnologia. A \\
Braskem também está presente nos \\
países: Argentina, Chile, Peru, \\
Colômbia, Venezuela, México, EUA, \\
Holanda, Alemanha e Cingapura. \\
\end{tabular} & $\begin{array}{l}\text { O grupo tem presença global com } \\
47 \text { sites industriais e } 6 \text { centros de } \\
\text { pesquisa e inovação na América do } \\
\text { Norte; } 59 \text { sites industriais e } 10 \\
\text { centros de pesquisa e inovação na } \\
\text { Europa; } 30 \text { unidades produtivas e } 4 \\
\text { centros de pesquisa e inovação na } \\
\text { Ásia; e } 9 \text { sites produtivos e } 1 \text { centro } \\
\text { de pesquisa e inovação na América } \\
\text { Latina }\end{array}$ & $\begin{array}{l}\text { A empresa tem sede global e } \\
\text { regional, centro de pesquisas } \\
\text { e unidades de fabricação em } \\
\text { países da América do Norte, } \\
\text { da } \\
\text { Ásia-Pacífico, Europa, } \\
\text { Oriente Médio e África; bem } \\
\text { como sede global (localizada } \\
\text { no Brasil) e unidades fabris na } \\
\text { América do Sul. }\end{array}$ \\
\hline $\begin{array}{l}\text { Área e mercados de } \\
\text { atuação }\end{array}$ & $\begin{array}{l}\text { Atuação nos mercados de adesivos, } \\
\text { agronegócio, borracha, construção, } \\
\text { indústria automotiva, lubrificantes, } \\
\text { tintas e varejo. }\end{array}$ & $\begin{array}{l}\text { Automotivo e aeroespacial, } \\
\text { produtos de consumo e cuidados de } \\
\text { saúde, energia e meio ambiente, } \\
\text { eletroeletrônico, edificação e } \\
\text { construção, e aplicações industriais. }\end{array}$ & $\begin{array}{l}\text { Transporte, infraestrutura, } \\
\text { meio ambiente e consumidor } \\
\text { final. }\end{array}$ \\
\hline
\end{tabular}

Fonte: Elaborado pelos autores. 
Realizou-se a coleta de dados a partir de pesquisa documental, registro de arquivos e entrevistas em profundidade semiestruturadas (YIN, 2010; GODOY, 2006; FLICK, 2004). Tais técnicas de coleta de dados são fundamentais para a triangulação dos dados coletados, que, segundo Yin (2010), ajuda a abordar problemas potenciais de validade do constructo, pois assim se tem o mesmo fenômeno com várias avaliações por meio de múltiplas fontes de evidência.

Yin (2010), Godoy (2006) e Gil (2009) consideraram que o exame de documentos pode trazer contribuições importantes para $\mathrm{o}$ estudo de caso. Complementarmente, a análise de documentos elaborados pela organização passa a ter informações que auxiliam na coleta de dados mediante observação ou entrevista (Gil, 2009). Segundo Yin (2010), os documentos são úteis e seu uso mais importante é para corroborar e aumentar a evidência de outras fontes.

Na Figura 5, são listados os sujeitos sociais da pesquisa e elencadas as fontes de evidências acessadas em cada unidade de análise investigada (BRASKEM, SOLVAY e BETA).

Figura 5 - Caracterização das fontes de evidências das empresas pesquisadas.

\begin{tabular}{|c|c|c|c|}
\hline & BRASKEM & SOLVAY & BETA \\
\hline & Caracterização & Caracterização & Carācterização \\
\hline 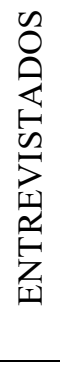 & $\begin{array}{l}\text { - Diretor Desenvolvimento } \\
\text { Sustentável } \\
\text { - Responsável pela área ambiental } \\
\text { em todos os sites da Braskem } \\
\text { - Coordenador de segurança e meio } \\
\text { ambiente das unidades de negócio } \\
\text { UNIPOL - SP } \\
\text { - Coordenadora de meio ambiente } \\
\text { na UNI2 - RS }\end{array}$ & $\begin{array}{l}\text { - Gerente de segurança e } \\
\text { meio ambiente } \\
\text { corporativo para a região } \\
\text { da América Latina. } \\
\text { - Gerente de RH e } \\
\text { responsável na América } \\
\text { do Sul pela área de } \\
\text { learning e Universidade } \\
\text { Corporativa }\end{array}$ & $\begin{array}{l}\text { - Gerente de SSMA } \\
\text { - Coordenadora de Sistema de Gestão } \\
\text { - Engenheira de Meio Ambiente e } \\
\text { Segurança } \\
\text { - Analista de RH encarregada de } \\
\text { treinamento }\end{array}$ \\
\hline 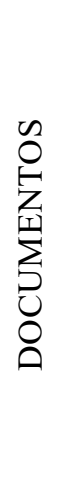 & $\begin{array}{l}\text { - Apresentação sobre Gestão } \\
\text { Ambiental } 2015 \\
\text { - Modelo de plano de aula de } \\
\text { educação ambiental } 2017 \\
\text { - Apresentação utilizada no } \\
\text { Workshop de Líderes para o } \\
\text { Desenvolvimento Sustentável } \\
\text { - Relatório Anual } 2015 \\
\text { - Dados disponíveis no site } \\
\text { institucional da empresa }\end{array}$ & $\begin{array}{l}\text { - Global Report } 2015 \\
\text { - Relatório Anual } \\
\text { Complementar } 2015 \\
\text { - Global Report } 2013 \\
\text { - Mapas de competências } \\
\text { para a figura da liderança } \\
2017 \\
\text { - Dados disponíveis no } \\
\text { site institucional da } \\
\text { empresa }\end{array}$ & $\begin{array}{l}\text { - Relatório de Sustentabilidade 2014- } \\
2015 \\
\text { - Atualização do Relatório de } \\
\text { Sustentabilidade } 2015 \\
\text { - Política de Saúde, Segurança e } \\
\text { Meio Ambiente } \\
\text { - Programa da Semana do Meio } \\
\text { Ambiente } 2016 \\
\text { - Lista de treinamentos de Meio } \\
\text { Ambiente } 2017 \\
\text { - Dados disponíveis no site } \\
\text { institucional da empresa }\end{array}$ \\
\hline
\end{tabular}

Fonte: Elaborado pelos autores.

Adotou-se, como processo de análise de dados os procedimentos de análise de conteúdo descritos por Bardin (2010), nos dois níveis de análise: no nível de cada entrevista, pelo processo de decifração que procura compreender a partir da fala de uma pessoa, e, no nível que busca a intercomunicação entre os indivíduos pelo processo da transversalidade temática. Desse modo, os dados foram interpretados a partir da categorização e da codificação.

Dentre as estratégias descritas por
Yin (2010), adotou-se também para análise dos dados a estratégia de contar com proposições teóricas que darão forma ao plano de coleta de dados que refletem um conjunto de questões de pesquisa, revisões da literatura, bem como a de repensar as explanações rivais que, como dito pelo autor, tenta definir e testar explanações rivais que geralmente funcionam com as demais estratégias. Estar aberto a essas estratégias permite que o trabalho encontre nos dados, explanações que irão de 
encontro às proposições teóricas contribuindo, assim, para a abordagem indutiva do trabalho.

Para complementar as estratégias gerais, buscou-se a utilização das subestratégias de análise: combinação de padrão, que segundo Yin (2010), é uma das mais desejáveis para análise de estudo de caso, pois pode fortalecer sua validade interna pelos resultados da análise, se houver coincidência entre os padrões e a síntese cruzada de casos, aplicáveis à análise de casos múltiplos.

A escolha da metodologia descrita anteriormente tem como finalidade atender ao objetivo geral da pesquisa, conforme sintetizado na matriz metodológica exposta na figura 6, na qual são destacadas as questões norteadoras que direcionaram tanto $\mathrm{o}$ roteiro de entrevistas quanto $\mathrm{o}$ roteiro para análise documental.

Figura 6 - Matriz metodológica.

\begin{tabular}{|c|c|c|c|c|c|}
\hline Objetivo Geral & $\begin{array}{l}\text { Objetivos } \\
\text { específicos }\end{array}$ & $\begin{array}{c}\text { Categoria de } \\
\text { análise }\end{array}$ & Dimensões & \begin{tabular}{|c|}
$\begin{array}{c}\text { Questões norteadoras } \\
\text { do roteiro }\end{array}$ \\
\end{tabular} & Autores \\
\hline \multirow{8}{*}{$\begin{array}{c}\text { Analisar como a } \\
\text { sistematização do } \\
\text { processo de } \\
\text { treinamento } \\
\text { ambiental pode } \\
\text { contribuir para o } \\
\text { desenvolvimento } \\
\text { de competências } \\
\text { individuais } \\
\text { associadas à } \\
\text { dimensão } \\
\text { ambiental da } \\
\text { sustentabilidade } \\
\text { em empresas do } \\
\text { setor químico } \\
\text { brasileiro. }\end{array}$} & \multirow{7}{*}{$\begin{array}{c}\text { Caracterizar o } \\
\text { processo de } \\
\text { treinamento } \\
\text { ambiental } \\
\text { desenvolvido } \\
\text { pelas empresas } \\
\text { químicas } \\
\text { estudadas. }\end{array}$} & \multirow{2}{*}{$\begin{array}{c}\text { Avaliação das } \\
\text { necessidades de } \\
\text { treinamento }\end{array}$} & $\begin{array}{c}\text { Gaps de } \\
\text { competência }\end{array}$ & $\begin{array}{c}\text { Como ocorre a análise de } \\
\text { necessidade de } \\
\text { treinamento ambiental? }\end{array}$ & $\begin{array}{l}\text { Abbad e Mourão, } \\
\text { (2012); Silva e } \\
\text { Menezes, (2012); } \\
\text { Narashimhan e } \\
\text { Ramanarayanan, } \\
\text { (2014); Salas e } \\
\text { Cannon-Bowers, } \\
\text { (2001). } \\
\end{array}$ \\
\hline & & & Abordagens & $\begin{array}{l}\text { Como são identificadas } \\
\text { novas necessidades de } \\
\text { treinamento ambiental? }\end{array}$ & \begin{tabular}{|c|} 
Arshad, Yusof, \\
Mahmood, \\
Ahmed e Akthar \\
$(2015)$. \\
\end{tabular} \\
\hline & & \multirow{3}{*}{$\begin{array}{c}\text { Desenvolvimento } \\
\text { e execução do } \\
\text { treinamento }\end{array}$} & $\begin{array}{c}\text { Escolha } \\
\text { modalidade }\end{array}$ & \multirow{3}{*}{$\begin{array}{c}\text { Como são desenvolvidos } \\
\text { os processos de } \\
\text { treinamento ambiental? } \\
\text { Como são definidas as } \\
\text { ferramentas, conteúdos e } \\
\text { métodos dos treinamentos } \\
\text { ambientais? }\end{array}$} & \multirow{3}{*}{$\begin{array}{l}\text { Abbad, Zerbini, } \\
\text { Carvalho e } \\
\text { Meneses (2006). }\end{array}$} \\
\hline & & & Sequência & & \\
\hline & & & Procedimentos & & \\
\hline & & & Transferência & \begin{tabular}{|c|} 
Como você avalia os \\
efeitos dos processos de \\
treinamento ambiental no \\
indivíduo, no grupo e na \\
empresa?
\end{tabular} & $\begin{array}{l}\text { Abbad, Pilati e } \\
\text { Pantoja (2003); } \\
\text { Baldwin e Ford } \\
\quad \text { (1988). }\end{array}$ \\
\hline & & $\begin{array}{l}\text { Avaliação do } \\
\text { treinamento }\end{array}$ & $\begin{array}{c}\text { Nível de } \\
\text { aprendizagem }\end{array}$ & $\begin{array}{l}\text { Como são avaliados os } \\
\text { resultados dos } \\
\text { treinamentos ambientais } \\
\text { desenvolvidos na } \\
\text { empresa? }\end{array}$ & \begin{tabular}{|c|} 
Kirkpatrick \\
(2010); Holton \\
$(1996) ;$ Baldwin e \\
Ford (1988); \\
Borges-Andrade \\
$(2006)$. \\
\end{tabular} \\
\hline & $\begin{array}{l}\text { Identificar nestas } \\
\text { empresas as } \\
\text { competências } \\
\text { individuais } \\
\text { consideradas } \\
\text { relevantes à } \\
\text { sustentabilidade } \\
\text { ambiental. }\end{array}$ & $\begin{array}{c}\text { Características } \\
\text { de competência } \\
\text { individual }\end{array}$ & $\begin{array}{l}\text { Gestão } \\
\text { Ambiental }\end{array}$ & \begin{tabular}{|c|} 
Quais são as \\
competências \\
consideradas essenciais \\
que as pessoas precisam \\
ter para que suas entregas \\
estejam alinhadas à \\
sustentabilidade \\
ambiental? \\
Como são mapeadas as \\
competências alinhadas à \\
dimensão ambiental das \\
pessoas na empresa?
\end{tabular} & $\begin{array}{c}\text { Van-Kleef e } \\
\text { Roome (2007); } \\
\text { Wiek, et al. (2011); } \\
\text { Roorda (2010); } \\
\text { Lambrechts, et al. } \\
\text { (2012); Barth, et al. } \\
\text { (2007); Eboli e } \\
\text { Mancini (2012); } \\
\text { Jabbour e Santos } \\
\text { (2008a-2008b). }\end{array}$ \\
\hline
\end{tabular}

Fonte: Elaborada pelos autores. 


\section{APRESENTAÇÃO E DISCUSSÃO DOS RESULTADOS}

São agrupados na figura 7 os treinamentos relevantes à sustentabilidade ambiental que foram mapeados nos casos investigados e que poderão ser foco de atenção por parte de outras empresas que atuam no setor químico brasileiro.

Figura 7 - Treinamentos ambientais para sustentabilidade ambiental mapeados nos casos investigados.

\begin{tabular}{|l|l|}
\hline Casos & Treinamentos ambientais para sustentabilidade ambiental \\
\hline BRASKEM & $\begin{array}{l}\text { Treinamento de Gestão Ambiental; Workshop de Líderes para Desenvolvimento Sustentável; Programa } \\
\text { de Desenvolvimento de Competências; Técnicas (PDCT) em Equipamentos e Processos Industriais; e } \\
\text { Treinamentos em Gestão de Ciclo de Vida. }\end{array}$ \\
\hline SOLVAY & $\begin{array}{l}\text { Treinamento em conscientização regulatória; Workshop de Competências Comportamentais; Programa } \\
\text { de Liderança Transformacional; Formação Geral Saúde, Segurança e Meio Ambiente; e Treinamento em } \\
\text { procedimentos em tratamento de resíduos. }\end{array}$ \\
\hline BETA & $\begin{array}{l}\text { Aspectos e Impactos Ambientais; Estocagem em Tanques, Tubulações e Áreas de Transferências; } \\
\text { Exposição a Monóxido de Carbono; Gerenciamento de Produtos Químicos; Gerenciamento de Resíduos; } \\
\text { GHS - Rotulagem de Produtos; e Programa Semana do Meio Ambiente. }\end{array}$ \\
\hline
\end{tabular}

Fonte: Elaborado pelos autores.

\subsection{Análise das Necessidades de Treinamento Ambiental}

A seguir, são apresentados os resultados das três empresas que compuseram a base desta pesquisa (Braskem, Solvay e Beta), destacando os dados referentes ao constructo estudado: treinamento ambiental.

Em relação à categoria 'avaliação das necessidades de treinamento', no que tange aos níveis de análise dos gaps de competências, nas três empresas estudadas houve alinhamento com a teoria em relação a todos os níveis de análise: organizacional, operacional e individual. $\mathrm{O}$ nível organizacional é identificado em cada uma das empresas tanto pelas demandas corporativas, quanto por demandas alinhadas às particularidades de cada negócio.

A 'avaliação das necessidades de treinamento' no nível operacional, ou também chamado por alguns autores de grupos e equipes, foi também evidenciada nas três empresas estudadas, sendo caracterizada por grupo de funções, por área funcional ou, até mesmo, por atividades específicas relacionadas ao meio ambiente, destacandose: a área de gestão ambiental, de manutenção, de pesquisa e desenvolvimento. A mesma situação de alinhamento foi encontrada nas empresas, no que diz respeito à avaliação da necessidade de treinamento no nível individual. Em todas as empresas estudas as fontes pelas quais são evidenciadas as necessidades de treinamento na dimensão individual são avaliação de desempenho e plano de desenvolvimento pessoal ou plano de carreira. A empresa Braskem destacou também, além dessas duas fontes, as auditorias internas que são realizadas pelo processo da ISO 14001.

Os dados encontrados nas três empresas estudadas, além de corroborarem os autores que indicam a necessidade da avaliação de necessidade de treinamento nos três níveis de abrangência, como Aguinis e Kraiger (2009), Abbad e Mourão (2012) e Narashimhan e Ramanarayanam (2014); também corroboram a literatura na qual as práticas de gestão de pessoas têm um papel importante no desenvolvimento da sustentabilidade organizacional, tendo como destaque o sistema de avaliação de desempenho e o plano de carreira (DAILY; HUANG, 2001; JABBOUR et al., 2010).

A segunda dimensão estudada, em relação à 'avaliação das necessidades de treinamento' foi a abordagem utilizada pelas empresas. Os dados mostram que as três empresas estudadas utilizam as duas abordagens: a reativa e a proativa. A primeira, em que as necessidades de treinamento são identificadas a partir do diagnóstico de gaps entre o desempenho esperado e o realizado pelo funcionário ou equipe, feito, principalmente, pela avaliação de desempenho e pelos resultados de auditorias associadas à estrutura da ISO 140001. A 
abordagem proativa está presente nas empresas por meio das necessidades de treinamento levantadas a partir das diretrizes estratégicas organizacionais, associadas à dimensão ambiental que envolvem os programas direcionados ao desenvolvimento de competências para a sustentabilidade, elaborados em uma dimensão corporativa. Os dados empíricos evidenciados nas três empresas pesquisadas mostram que elas analisam a necessidade de treinamento tanto a partir da identificação de gaps entre o resultado esperado e o realizado pelos funcionários, quanto com base nos objetivos estratégicos organizacionais, corroborando a base teórica estabelecida por Arshad et al. (2015). Os autores afirmam a existência de duas abordagens que podem ser utilizadas na avaliação das necessidades de treinamento: reativa e proativa.

A análise da categoria avaliação da necessidade de treinamento aponta também para a necessidade de integração da área de gestão de pessoas nesse processo por meio de seus subsistemas de avaliação de desempenho e plano de carreira ou desenvolvimento individual, evidenciando, assim como visto na literatura, a necessidade de integração desses subsistemas e de seu alinhamento aos intentos estratégicos, no que diz respeitos à sustentabilidade o que corrobora Colbert e Kurucz (2007), Jabbour (2011) e Jackson et al. (2014) que destacam o papel das estratégias e práticas de gestão de pessoa no apoio aos objetivos organizacionais em busca da sustentabilidade.

\subsection{Desenvolvimento e Execução do Treinamento Ambiental}

A segunda categoria analisada foi $o$ 'desenvolvimento e execução do treinamento, tendo como base as dimensões: escolha da modalidade, sequência do treinamento e procedimentos.

$\mathrm{Na}$ dimensão das modalidades utilizadas nos treinamentos ambientais, nas três empresas observaram-se as propriedades de modalidade treinamento presencial e a distância, como por exemplo o treinamento em Gestão Ambiental da Braskem, modalidade presencial e conteúdo que aborda os vários tipos de resíduos e de impactos e o treinamento "Aspectos e Impactos Ambientais" da empresa Solvay que é na modalidade a distância e aborda os principais objetivos organizacionais visando redução dos impactos ambientais causados pelas operações da empresa. Apesar da utilização das modalidades presencial e e-learning, o que se evidenciou nos dados coletados nas empresas é o destaque da modalidade a distância, tendo como argumento para sua expansão, a facilidade de abrangência e generalização do treinamento, pela facilitação de realização do treinamento em termos de disponibilidade de tempo e, principalmente, redução de custos que essa modalidade apresenta. As modalidades encontradas alinham-se parcialmente à base teórica desenvolvida por Abbad et al. (2006). Essa base mostra a aplicação das modalidades presencial, semipresencial e a distância como metodologias aplicáveis aos treinamentos ambientais, uma vez que não foi identificada nas empresas pesquisadas a utilização da modalidadesemipresencial.

A segunda dimensão analisada foi a da sequência do treinamento pautada em uma hierarquia de treinamento partindo de menor para maior nível de complexidade, conforme definido por Abbad et al. (2006). Essa dimensão, no entanto, não foi encontrada nas empresas estudadas. A partir das evidências coletadas nas empresas estudadas, pode-se afirmar que, no que tange aos treinamentos ambientais não há um desenvolvimento em dimensões sequenciais por nível de complexidade, caracterizando, assim, um desalinhamento entre a teoria e a prática em relação a essa dimensão.

Para completar a análise da categoria "desenvolvimento e execução de treinamento", foi investigada a dimensão dos procedimentos utilizados nos programas de treinamento ambiental. No que concerne às ferramentas e aos recursos utilizados na execução dos treinamentos, evidenciou- se, nas três empresas, uma liberdade para cada unidade de negócio buscar os recursos necessários às suas necessidades. Foi 
identificada nas três empresas a utilização de treinamentos internos e externos, de treinamentos desenvolvidos na própria empresa e de treinamentos desenvolvidos por empresas contratadas, contratação de palestrantes, realização de workshops, eventos de simulação, atividades lúdicas como jogos, teatros. Com isso, as empresas mostram-se alinhadas à base teórica desenvolvida por autores como; Ramus (2002), Unnikrishann e Hedge (2007), Jabbour (2013), Abbad et al. (2006).

\subsection{Avaliação do Treinamento Ambiental}

A terceira categoria analisada foi a avaliação de treinamento por meio das dimensões: transferência e níveis de aprendizagem.

No que tange à dimensão transferência, as propriedades investigadas foram: generalização, manutenção, transferência horizontal e transferência vertical. A generalização foi evidenciada nas três empresas estudadas, com ampliação do conceito estabelecido por Baldwin e Ford (1998), da aplicação no ambiente de trabalho do que foi aprendido para: aplicação de um negócio para outro, empresa Beta; aplicação para fornecedores, empresa Solvay; e para o setor industrial, Braskem. Dessa forma, os dados corroboram o desenvolvimento da capacidade de resposta aos impactos sociais e ambientais por meio da interação e diálogo com os stakeholders, constituindo uma competência societal, conforme Brunstein et al. (2012).

Como a propriedade de manutenção não foi evidenciada nas empresas estudadas, pode-se dizer que pelos dados analisados dessas empresas, a dimensão da transferência é alinhada à propriedade de generalização, corroborando parcialmente Baldwin e Ford (1988), que estabelecem a generalização e a manutenção como perspectiva de transferência.

Das propriedades de transferência horizontal e vertical, estabelecidas por Abbad et al. (2003), a primeira não foi identificada na empresa Beta, mas estão presentes nas evidências das empresas Braskem, considerando transferência em níveis organizacionais estratégico e tático, e Solvay, que apresenta a transferência em áreas funcionais, mas também amplia para uma dimensão setorial por meio da participação na ABIQUIM, de forma que a aprendizagem é transferida para outras empresas do setor, corroborando, assim, o desenvolvimento da competência societal (BRUNSTEIN et al., 2012).

A propriedade de transferência vertical foi evidenciada nas três empresas estudadas, sendo considerada uma transmissão da aprendizagem top-down, com destaque para a atuação da liderança nesse processo de transferência da aprendizagem. Tais evidências corroboram Arnaut, et al. (2012) que afirmam a importância do papel da liderança para o desenvolvimento da gestão ambiental proativa, bem como corroboram Burke e Hutchin (2007), que destacam o papel do suporte dos superiores no processo de transferência do treinamento.

A dimensão 'avaliação de treinamento ambiental' mostrou-se, nas três empresas estudadas, ser uma fase complexa e de difícil realização, o que corrobora a base teórica desenvolvida por Salas e CannonBowers (2001) ao afirmar que avaliação de treinamento se trata de um trabalho complexo. Todas as propriedades da dimensão níveis de aprendizagem da avaliação de treinamento apresentadas na literatura (reação, aprendizagem, comportamento, desempenho e resultado) não foram identificadas nas três empresas, no que diz respeito aos treinamentos ambientais.

A propriedade da avaliação no nível de reação foi identificada nas empresas Solvay e Beta, sendo atribuída aos resultados dessa avaliação a contribuição para o planejamento e execução de novos eventos de treinamento ambiental, bem como para melhorias nas ações existentes. Esses resultados estão alinhados à literatura sobre a importância da avaliação da reação dos treinados aos eventos de treinamento (KIRKPATRICK, 2010).

O nível de aprendizagem é avaliado nas empresas Braskem e Beta, sendo que a primeira apresenta esse processo de avaliação 
realizado principalmente naqueles associados às normas regulamentadoras, como ISO 14000, pautado em processo de auditoria que verifica o nível do conhecimento do profissional que tenha participado de treinamento ambiental. A empresa Beta descreveu o processo a partir da aplicação de uma prova de verificação de aprendizagem do conteúdo apresentado no treinamento, com objetivo de diagnosticar se houve a compreensão. Na empresa Solvay não houve relato de avaliação de aprendizagem nos treinamentos ambientais. Com base nesses resultados, pode-se afirmar que a avaliação no nível de aprendizagem, nas empresas que a aplicam ao treinamento ambiental, alinha-se parcialmente à literatura (KIRKPATRICK, 2010; HOLTON，1996; KIRKPATRICK; KIRKPATRICK, 2010).

A avaliação no nível comportamento foi identificada nas três empresas estudadas. A Braskem realiza essa avaliação por meio de auditoria interna anual que verifica, junto ao líder, o comportamento dos funcionários associados aos treinamentos que ele participou. As empresas Solvay e Beta fazem essa avaliação por meio da avaliação de desempenho. Esses resultados corroboram a literatura estabelecida sobre avaliação de treinamento no nível comportamento, no que diz respeito à verificação da mudança comportamental no ambiente de trabalho da pessoa treinada. No entanto, não se identificou associação dos resultados dessa avaliação à investigação das possíveis causas da não mudança comportamental, como por exemplo, suporte organizacional, apoio da liderança, falta de um sistema de recompensas tanto intrínsecas quanto extrínsecas (KIRKPATRICK, 2010; HOLTON, 1996; KIRKPATRICK; KIRKPATRICK, 2010).

A avaliação do treinamento no nível desempenho, conforme estabelecido por Holton (1996) está presente nas três empresas, associada às auditorias anuais internas pela Braskem; à avaliação de desempenho pela Solvay; e a um sistema de avaliação do próprio treinamento pela empresa Beta. No entanto, as três empresas apresentam dificuldades em relação a essa avaliação.

A avaliação no nível resultados para os treinamentos ambientais é executada nas empresas Braskem e Solvay. Em ambas as empresas, a avaliação associa-se à melhoria nos resultados organizacionais, incluindo: melhoria no controle de efluentes, redução de gases do efeito estufa, eficiência energética, pós-consumo. A Braskem associa a eficácia dos treinamentos ambientais às melhorias dos indicadores desenvolvidos a partir dos objetivos estratégicos na dimensão ambiental para 2015. A Solvay avalia os resultados a partir dos desafios estabelecidos pelo time de coordenadores do programa Solvay Way nos eixos: consumidor, empregados, planeta, investidor, fornecedores e comunidades. Com base nos processos estabelecidos por essas empresas, pode-se afirmar que elas estão alinhadas à base teórica definida por Kirkpatrick (2010); Holton (1996); Kirkpatrick e Kirkpatrick (2010) e BorgesAndrade (2006), no que diz respeito à avaliação de treinamento no nível resultados que possam ter efeitos no longo prazo, de acordo com as metas estabelecidas por cada empresa com foco no longo prazo: Braskem objetivos para 2020, Solvay e Beta para 2025, conforme relatórios anuais de sustentabilidade das empresas.

A categoria de 'avaliação de treinamento' mostrou-se presente nas três empresas, no entanto, não no formato de todos os níveis de análise apresentados pela literatura pelos autores supracitados. Contudo, apesar de não haver um processo estruturado de avaliação de treinamento ambiental nas empresas estudadas, todas associam os resultados alcançados dos avanços organizacionais, no que diz respeitos à melhoria dos resultados ambientais alcançados por cada uma das empresas, aos programas de treinamento implementados.

Essas evidências corroboram Jabbour (2013) quando destaca o treinamento ambiental como um fator de sucesso para a gestão ambiental com o fornecimento de ferramentas, métodos e técnicas que contribuem para o desenvolvimento de estratégias organizacionais para minimização dos impactos ambientais, sociais e 
econômicos, alinhados aos pilares do Triple Botton Line. Ao mesmo tempo, essa avaliação foi associada, principalmente, ao processo de avaliação de desempenho, mostrando novamente a importância do alinhamento dos subsistemas da área de gestão de pessoas, corroborando Colbert e Kurucz (2007) e Jackson et al.(2014).
$\mathrm{Na}$ figura $8 \quad \mathrm{o}$ constructo 'Treinamento Ambiental' é reorganizado em categorias e dimensões e suas propriedades descritoras são apresentadas a partir do confronto dos dados empíricos (discussão dos casos BRASKEM, SOLVAY e BETA) com a literatura.

Figura 8 - Discussão agregada dos treinamentos ambientais realizados pelas empresas investigadas.

\begin{tabular}{|c|c|c|c|c|c|}
\hline \multirow{9}{*}{ 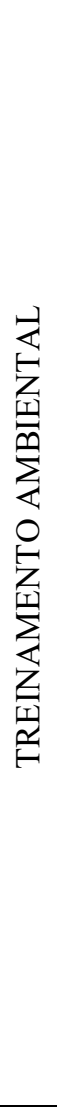 } & \multirow{2}{*}{$\begin{array}{l}\text { CATEGORIAS } \\
\text { DE ANÁLISE }\end{array}$} & \multirow{2}{*}{ DIMENSÕES } & \multicolumn{3}{|c|}{ PROPRIEDADES DESCRITORAS } \\
\hline & & & BRASKEM & SOLVAY & BETA \\
\hline & \multirow{2}{*}{$\frac{\frac{\text { Avaliação das }}{\text { necessidades de }}}{\underline{\text { treinamento }}}$} & $\begin{array}{c}\text { Gaps de } \\
\text { competência }\end{array}$ & $\begin{array}{c}\text { Organizacional } \\
\text { Operacional } \\
\text { Individual } \\
\end{array}$ & $\begin{array}{c}\text { Organizacional } \\
\text { Operacional } \\
\text { Individual } \\
\end{array}$ & $\begin{array}{c}\text { Organizacional } \\
\text { Operacional } \\
\text { Individual }\end{array}$ \\
\hline & & Abordagens & $\begin{array}{c}\text { Reativa } \\
\text { Proativa }\end{array}$ & $\begin{array}{c}\text { Reativa } \\
\text { Proativa }\end{array}$ & $\begin{array}{c}\text { Reativa } \\
\text { Proativa }\end{array}$ \\
\hline & \multirow{3}{*}{$\underline{\text { Desenvolvimento }}$} & $\begin{array}{c}\text { Escolha } \\
\text { modalidade }\end{array}$ & $\begin{array}{l}\text { Presencial } \\
\text { A distância }\end{array}$ & $\begin{array}{l}\text { Presencial } \\
\text { A distância }\end{array}$ & $\begin{array}{l}\text { Presencial } \\
\text { A distância }\end{array}$ \\
\hline & & Sequência & $\begin{array}{c}\text { Menos complexa } \\
\text { Mais complexa }\end{array}$ & $\begin{array}{c}\text { Ausência de } \\
\text { evidências }\end{array}$ & $\begin{array}{l}\text { Ausência de } \\
\text { evidências }\end{array}$ \\
\hline & & Procedimentos & $\begin{array}{c}\text { Definição objetivos } \\
\text { Escolha } \\
\text { ferramentas e } \\
\text { recursos }\end{array}$ & $\begin{array}{c}\text { Definição objetivos } \\
\text { Escolha } \\
\text { ferramentas e } \\
\text { recursos }\end{array}$ & $\begin{array}{l}\text { Escolha } \\
\text { ferramentas e } \\
\text { recursos }\end{array}$ \\
\hline & \multirow{2}{*}{$\underline{\text { Avaliação }}$} & Transferência & $\begin{array}{c}\text { Generalização } \\
\text { Horizontal } \\
\text { Vertical } \\
\text { Fatores de } \\
\text { influência }\end{array}$ & $\begin{array}{c}\text { Generalização } \\
\text { Horizontal } \\
\text { Vertical }\end{array}$ & $\begin{array}{c}\text { Generalização } \\
\text { Manutenção } \\
\text { Vertical } \\
\text { Fatores de } \\
\text { influência }\end{array}$ \\
\hline & & $\begin{array}{c}\text { Nivel de } \\
\text { aprendizagem }\end{array}$ & $\begin{array}{c}\text { Reação } \\
\text { Aprendizagem } \\
\text { Comportamento } \\
\text { Desempenho } \\
\text { Resultado }\end{array}$ & $\begin{array}{c}\text { Comportamento } \\
\text { Desempenho } \\
\text { Resultado }\end{array}$ & $\begin{array}{c}\text { Reação } \\
\text { Aprendizagem } \\
\text { Comportamento } \\
\text { Desempenho }\end{array}$ \\
\hline
\end{tabular}

Fonte: elaborado pelos autores.

\subsection{Competências Individuais alinhadas à Sustentabilidade Ambiental}

A análise da categoria das características das competências individuais para a sustentabilidade nas empresas estudadas busca identificar tais competências de modo que possam ser tomadas como base para análise do treinamento ambiental tratado na seção anterior. Análise das competências individuais para a sustentabilidade foi feita a partir da dimensão de seu alinhamento com a gestão ambiental. Evidenciou-se que as competências individuais alinhadas à sustentabilidade ambiental descritas na literatura, conforme figura 9, foram identificadas nas empresas estudadas.

Figura 9 - Competências individuais alinhadas à sustentabilidade mapeadas nas empresas estudadas.

\begin{tabular}{|l|c|c|c|}
\hline $\begin{array}{l}\text { Propriedades das competências individuais alinhadas à } \\
\text { sustentabilidade }\end{array}$ & BRASKEM & SOLVAY & BETA \\
\hline Orientação Saúde Segurança Meio Ambiente & $\mathrm{X}$ & $\mathrm{X}$ & $\mathrm{X}$ \\
\hline Trabalho em equipe & $\mathrm{X}$ & $\mathrm{X}$ & $\mathrm{X}$ \\
\hline Assumir responsabilidade & $\mathrm{X}$ & $\mathrm{X}$ & \\
\hline Visão sistêmica & $\mathrm{X}$ & $\mathrm{X}$ & $\mathrm{X}$ \\
\hline
\end{tabular}




\begin{tabular}{|l|c|c|c|}
\hline Maximização resultados & $\mathrm{X}$ & $\mathrm{X}$ & \\
\hline Comunhão com meio ambiente & $\mathrm{X}$ & $\mathrm{X}$ & $\mathrm{X}$ \\
\hline Resiliência & $\mathrm{X}$ & & \\
\hline Busca por conhecimento & $\mathrm{X}$ & & \\
\hline Atitude de colaboração & $\mathrm{X}$ & & \\
\hline Comprometimento com sustentabilidade & $\mathrm{X}$ & & \\
\hline Antecipação desafios & $\mathrm{X}$ & & \\
\hline Raciocínio crítico & $\mathrm{X}$ & & \\
\hline Capacidade de comunicação & $\mathrm{X}$ & & \\
\hline Senso de oportunidade & $\mathrm{X}$ & & \\
\hline Mente aberta & & $\mathrm{X}$ & \\
\hline Coragem & & $\mathrm{X}$ & \\
\hline Iniciativa & & $\mathrm{X}$ & \\
\hline Orientação clientes & & $\mathrm{X}$ & \\
\hline Impactos e influências & & $\mathrm{X}$ & \\
\hline Desenvolvimento dos outros & & $\mathrm{X}$ & \\
\hline Planejamento do trabalho & & & $\mathrm{X}$ \\
\hline
\end{tabular}

Fonte: Elaborado pelos autores.

Os dados apresentados na figura 9 demostram ainda que algumas propriedades de competências individuais identificadas nas empresas não estão previstas na literatura (levantadas inicialmente na figura 3), sendo elas: 'iniciativa'; mente aberta', 'trabalho em equipe'; 'atitude de colaboração'. Portanto, essas novas propriedades corroboram a literatura, no que diz respeito à dimensão econômica do treinamento ambiental para sustentabilidade, pela perspectiva da inovação, como as propriedades 'iniciativa' e 'mente aberta'; e na dimensão social da sustentabilidade, pela perspectiva da diversidade, como as propriedades 'trabalho em equipe', 'atitude de colaboração'.

A partir dos resultados analisados sobre o processo do treinamento ambiental e a caracterização das competências individuais para sustentabilidade ambiental, pode-se fazer a proposição de um modelo descritivo de treinamento ambiental estratégico para desenvolvimento de competências individuais para a sustentabilidade ambiental das empresas do setor químico brasileiro. Esse modelo é apresentado na Figura 10.

Figura 10 - Modelo Descritivo do Treinamento Ambiental Estratégico

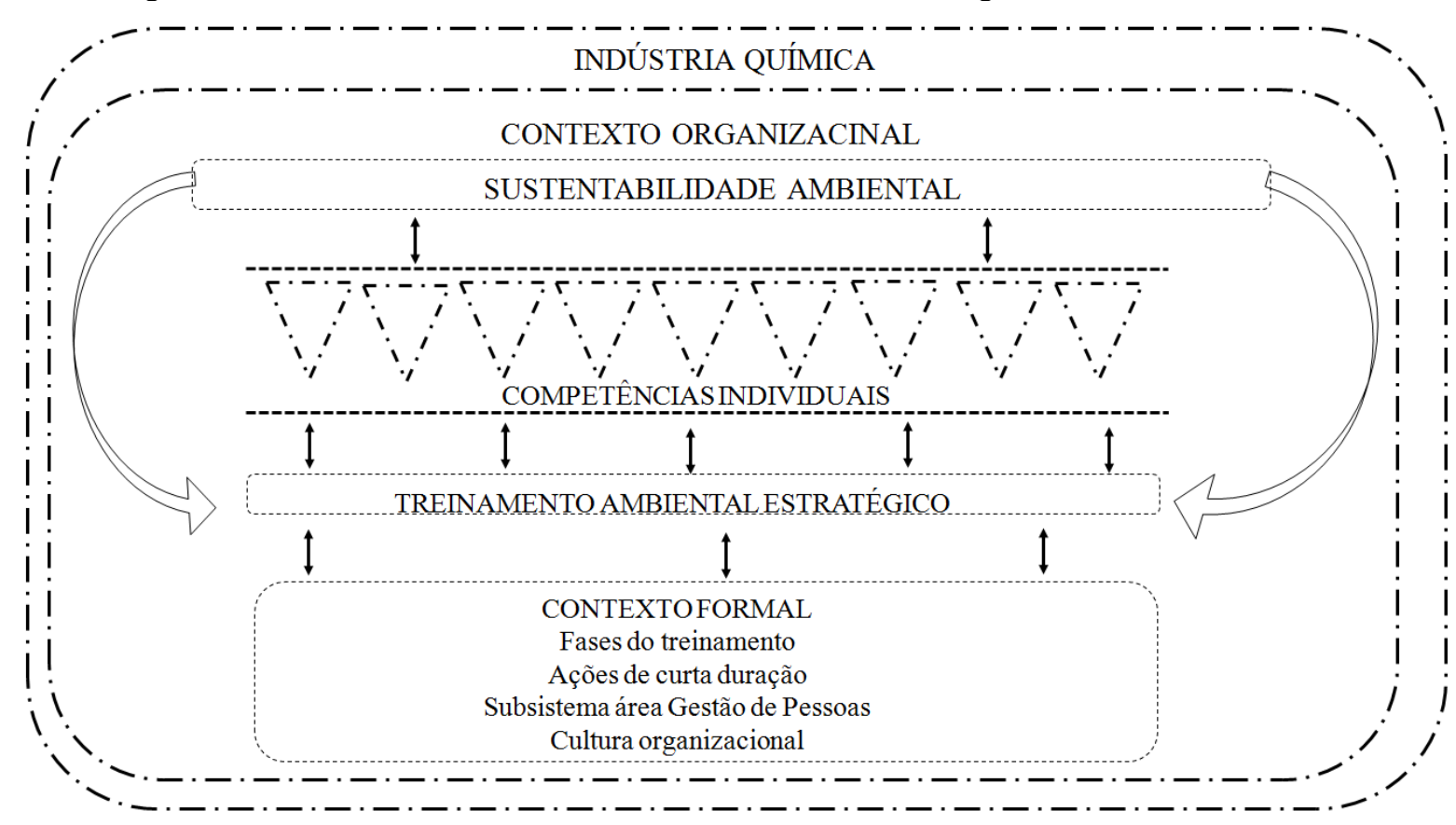

Fonte: Elaborado pelos autores. 
O modelo descreve o processo de geração de competências individuais que são caracterizadas em uma posição crescente de suporte ao desenvolvimento sustentabilidade ambiental.

O conceito de treinamento ambiental toma uma dimensão estratégica, sendo considerado como um processo de educação continuada, visando atender aos objetivos e propósitos da gestão ambiental corporativa, desenvolvendo todos os níveis organizacionais para integrar o desempenho da organização às questões ambientais. $\mathrm{O}$ contexto formal é caracterizado pelas fases do treinamento: a avaliação da necessidade de treinamento, abrangendo os níveis estratégico, tático e operacional, com uma abordagem proativa; o desenvolvimento e execução do treinamento com escolha de modalidades, métodos, conteúdos e processo de comunicação alinhados às características dos treinandos; e avaliação dos resultados dos treinamentos em cada um dos três níveis organizacionais.

O Contexto formal abrange: ações educacionais de curta duração, tais como, palestras rápidas, diálogos frequentes sobre meio ambiente, boletins informativos ambientais; comunicação sistemática de temas ambientais; formação de grupos ou comitês heterogêneos que possibilitem trocas de experiências e informações no que diz respeito às questões ambientais.

Ainda, considerando-se o contexto formal, evidencia-se $o$ papel dos subsistemas da área de gestão de pessoas, como sistema de plano de carreira e avaliação de desempenho, como estratégias da área que contribuem para o desenvolvimento dos treinamentos ambientais. Da mesma forma, o apoio da alta liderança bem como dos líderes diretos são elementos de um contexto formal estabelecido pela cultura organizacional que cooperam para o êxito dos treinamentos ambientais, bem como o desenvolvimento de competências individuais para a sustentabilidade ambiental.

\section{CONSIDERAÇÕES FINAIS}

Ao se analisar o processo de treinamento ambiental desenvolvido pelas três grandes empresas do setor químico brasileiro estudadas, conseguiu-se caracterizar de forma descritiva as fases do processo de treinamento ambiental desenvolvidas, atendendo-se, assim, ao primeiro objetivo específico. Da mesma forma, identificaram-se as competências individuais consideradas relevantes à sustentabilidade ambiental, atingindo-se, assim o segundo objetivo específico.

A partir desses objetivos, pode-se alcançar o objetivo geral sobre o treinamento ambiental por meio da estruturação de suas fases alinhadas aos objetivos organizacionais, no que diz respeito aos intentos estratégicos; no que tange à sustentabilidade, contribui para o desenvolvimento de competências individuais essenciais à sustentabilidade ambiental. Também se identificou a importância da integração dos subsistemas de avaliação de desempenho e plano de carreira ou desenvolvimento individual aos programas de treinamento ambiental no que diz respeito à sustentabilidade. A partir desses resultados, pode-se propor um modelo descritivo e confirmar a proposição de que o processo de treinamento ambiental pode potencializar o desenvolvimento de competências individuais essenciais à sustentabilidade das empresas do setor químico brasileiro, considerando-se que o processo de treinamento ambiental é voltado para estimular e desenvolver competências individuais alinhadas à estratégia organizacional, a partir dos gaps de competência identificados.

As contribuições que poderão advir deste estudo, para o contexto organizacional, estão relacionadas à descrição das fases do processo de treinamento ambiental desenvolvidas pelas empresas estudadas, podendo servir de benchmark para outras empresas do setor, bem como apresentar para as empresas estudadas possibilidade de aprimoramento de seu processo a partir do modelo descritivo apresentado. Além disso, são agrupadas as competências individuais para sustentabilidade ambiental que foram mapeadas nos casos investigados e que 
poderão ser foco de atenção por parte de outras empresas que atuam no setor químico brasileiro. No contexto acadêmico e para a comunidade científica, este estudo poderá vir a contribuir para a investigação acerca da relação entre os constructos treinamento ambiental e sustentabilidade, aprofundando a investigação sobre os temas.

As limitações desta pesquisa pautamse, essencialmente, na própria estratégia de pesquisa, que não poderia ser levado à generalização, bem como na necessidade de aprofundamento do próprio estudo envolvendo outras áreas organizacionais ou a ampliação para investigação de unidades das empresas situadas fora do Brasil, o que abre possibilidade para continuidade do estudo.

\section{AGRADECIMENTOS}

Os autores agradecem ao apoio do Conselho Nacional de Desenvolvimento Científico e Tecnológico ( $\mathrm{CNPq}$ ) pelas Bolsas de Produtividade (autores 2 e 3 ).

\section{REFERÊNCIAS}

ABBAD, G.; PILATI, R.; PANTOJA, M. J. Avaliação de treinamento: análise da literatura e agenda de pesquisa.

Revista de Administração da USP, v. 38, n. 3, p. 205-218, 2003.

ABBAD, G. D. S.; MOURÃO, L. Avaliação de necessidades de TD\&E: proposição de um novo modelo. Revista de Administração Mackenzie, v. 13, n. 6, p. 107-137, 2012.

ABBAD, G. S.; ZERBINI, T.; CARVALHO, R. S.; MENESES, P. P. M. Planejamento instrucional em TD\&E. In: BORGES-ANDRADE, J. E.; ABBAD, G. S.; MOURÃO, L (Orgs.). Treinamento, Desenvolvimento e Educação em Organizações e Trabalho fundamentos para a gestão de pessoas. Porto Alegre: Artmed, $p$. 289-322, 2006.

ABIQUIM - Associação Brasileira das
Indústrias Químicas (2020). Disponível em

https://abiquim.org.br/programas/historico . Acesso em: 01 mar. 2021.

AGUINIS, H. E.; KRAIGER, K. Benefits of training and development for individuals and teams, organizations, and society. Annual Review of Psychology, v. 60 , p. $451-474,2009$

ARSHAD, M. A.; YUSOF, A. N. M.; MAHAMOOD, A.; AHMED, A. E.; AKHTAR, S. A Study on Training Needs Analysis (TNA) Process among Manufacturing Companies dRegistered with Pembangunan Sumber Manusia Berhad (PSMB) at Bayan Lepas Area, Penang, Malaysia. Mediterranean Journal of Social Sciences, v. 6, n. 4, p. 670-678, 2015

BARDIN, L. Análise de Conteúdo. Lisboa/Portugal: Edições 70, 5 ed, 2010

BARTH, M.; GODEMANN, J.; RIECKMANN, M.; STOLTENBERG, U. Developing key competencies for sustainable development in higher education. International Journal of Sustainability in Higher Education, v. 8, n. 4, p. 416-430, 2007.

BALDWING, T. T.; FORD, J. Transfer of Training: A Review and Directions for Future Research. Personnel Psychology, v. 41, n. 1, p. 63-105, 1988.

BORGES-ANDRADE, J. E. Avaliação integrada e somativa em TD\&E. In: BORGES-ANDRADE, J. E.; ABBAD, G. S.; MOURÃO, L (Orgs.).

Treinamento, desenvolvimento e educação em organizações e trabalho: fundamentos para a gestão de pessoas. Porto Alegre: Artmed, p. 343-358, 2006.

BURKE, L. A.; HUTCHINS, H. M. Training transfer: An integrative literature review. Human resource 
development review, v.6, n.3, p. 263296, 2007.

BRUNDTLAND, G. H. Our Common Future: World Commission on Environmental Development. The Brundtland-Report Oxford University Press, Oxford: UK, 1987.

BRUNSTEIN, J.; SCARTEZINI, V. N.; RODRIGUES, A. L. Sustentabilidade na educação corporativa e o desenvolvimento de competências societais. Organizações e Sociedade, v. 19, n.63, p. 583-598, 2012.

CLARO, P. B. O., CLARO, D. P.; AMÂNCIO, R. Entendendo o conceito de sustentabilidade nas organizações.

Revista de Administração da Universidade de São Paulo, São Paulo, v. 43, n. 4, p. 289-300, out./nov./dez, 2008.

COLBERT, B. A.; KURUCZ, E. C. Three conceptions of triple bottom line business sustainability and the role for HRM. Human Resource Planning, v. 30, n. 1, p. 21-29, 2007.

DAILY, B. F.; HUANG, S. C. Achieving sustainability through attention to human resource factors in environmental management.

International Journal of Operations e Production Management, v. 21, n. 12, p. 1539-1552, 2001.

DERMOL, V.; CATER, T. The influence of training and training transfer factors on organisational learning and performance. Personnel review, v. 42, n. 3, p. 324-348, 2013.

EBOLI, M.; MANCINI, S. Corporate education for sustainability.

International Journal of Environment and Sustainable Development, v. 11, n. 4, p. 339-354, 2012.

EHNERT, I; Harry, W. Recent developments and future prospects on sustainable human resource management: introduction to the special issue. Management Revue, v. 23, n. 3, p. 221-238, 2012.

ELKINGTON, J. Canibais de garfo e faca: seria sinal de progresso se um canibal utilizasse garfo e faca para comer? Trad. Ramalho P. M., São Paulo: Makron Books, 2001.

FISCHER, A. L. Um resgate conceitual e histórico dos modelos de gestão de pessoas. In: FLEURY, M. T. L.

(Coord.). As Pessoas na Organização. São Paulo: Editora Gente, 2002. p. 1134.

FLICK, U. Questões de Pesquisa. In: FLICK, U.(Org.) Uma introdução à pesquisa qualitativa. 2. ed. Porto Alegre: Bookman, 2004. p. 63-68.

GIL, A. C.Estudo de Caso:

Fundamentação científica subsídios para coleta e análise de dados como redigir o relatório. São Paulo: Atlas, 2009.

GODOY, A. S. Estudo de caso qualitativo. In: GODOI, C. K.; BANDEIRA-DE-MELO, R.; SILVA, A. B. (Orgs.) Pesquisa qualitativa em estudos organizacionais - paradigmas, estratégias e métodos. São Paulo: Saraiva, 2006. p. 115-146.

HOLTON. E. F. The Flawed four-level evaluation model. Human resource development quarterly, v. 7, n. 1, p. 521, 1996.

JABBOUR, C. J. C. Environmental training in organizations: From a literature review to a framework for future research. Resources, Conservation and Recycling, v. 74, p. 144-155, 2013.

JABBOUR, C. J. C. How green are 
HRM practices, organizational culture, learning and teamwork? A Brazilian study. Industrial and Commercial Training, v. 43, n. 2, p. 98-105, 2011.

JABBOUR, C. J. C., TEIXEIRA, A. A., OLIVEIRA, J. H. C. E SOUBIHIA, D. F. Managing environmental training in organizations: theoretical review and proposal of a model. Management of Environmental Quality: An International Journal, v. 21, n. 6, p. 830-844, 2010.

JABBOUR, C. J. C.; SANTOS, F. C. A. Relationships between human resource dimensions and environmental management in companies: proposal of a model. Journal of Cleaner Production, v. 16, n. 1, p. 51-58, 2008a.

JABBOUR, C. J. C.; SANTOS, F. C. A. The central role of human resource management in the search-for sustainable organizations. The International Journal of Human Resource Management. v. 19, n. 12, p. 21332154, 2008b.

JACKSON, S. E.; SCHULER, R. S.; JIANG, K. An aspirational framework for strategic human resource management. The Academy of Management Annals, v. 8, n. 1, p. 1-56, 2014.

KIRKPATRICK, D. Great ideas revisited. Training and Development, v. 50, n. 1, p. 54-59, 2010.

KIRKPATRICK, D. L.; KIRKPATRICK, J. D. Como Avaliar Programas de Treinamento de Equipes. Trad. Lamensdorf, J. H. Senac: Rio de Janeiro, 2010.

LAMBRECHTS, W.; MULÀ, I.; CEULEMANS, K.; MOLDEREZ, I.; GAEREMYNCK, V. The integration of competences for sustainable development in higher education: an analysis of bachelor programs in management. Journal of Cleaner Production, v. 30, p. 1-9, 2012.

MASON, J. Planning and designing qualitative research. In: MASON, J. Qualitative Researching. London: Sage, 1996. p. 9-19.

MUNCK, L.; BORIM-DE-SOUZA, R. Sustainability and competencies in organisational contexts: a proposal of a model of interaction. International Journal of Environment and Sustainable Development, v. 11, n. 4, p. 394-411, 2012.

MORAES, F. C. C.; EBOLI, M. Concepção e Modelagem do Projeto de Educação Corporativa. In: EBOLI, M. et $a l$. Educação corporativa: fundamentos, evolução e implantação de projetos. São Paulo: Atlas, 2010. p. 275-296.

NARASIMHAN, G. V.; RAMANARAYANAN, C. S. Analysis of Training Needs Assessment and Implementation - A Comparative Study of Public and Private Sector Banks.

Indian Journal of Commerce and Management Studies, v. 5, n. 3, p. 71, 2014.

RAMUS, C. A. Encouraging innovative environmental actions: what companies and managers must do. Journal of world business, v. 37 , n. 2, p. 151-164, 2002.

ROORDA, N. Sailing on the winds of change: The Odyssey to sustainability of the universities of applied sciences in the Netherlands. Tese de Doutorado. Maastricht university. 2010.

SALAS, E.; CANNON-BOWERS, J. A. The science of training: A decade of progress. Annual review of psychology, v. 52, n. 1, p. 471-499, 2001.

SANTOS, J. G. C. et al. Innovation and 
socio-environmental sustainability: a comparative study of Brazilian and European firms. Revista de Administração da UFSM, v. 12, n. 5, p. 995-1012, 2019.

SEVERO, E. A.; DE GUIMARÃES, J. C. F.; MORAIS, L. A SUSTENTABILIDADE AMBIENTAL NA PERSPECTIVA DAS GERAÇÕES DO SUL DO BRASIL. Revista Eletrônica de Estratégia \& Negócios, v. 12, n. 2, p. 85-112, 2020.

SEVERO, E. A.; DORION, E. C. H.; GUIMARÃES, J. C. F. Cleaner production and environmental management as sustainable product innovation antecedents: A survey in Brazilian industries. Journal of Cleaner Production, v. 142, p. 87-97, 2017.

SILVA, A.; MOURA, J. A.; ZANELLI, J. C. O valor estratégico do treinamento, desenvolvimento e educação (T\&D) para formação de competências. Revista Psicologia Organizações e Trabalho, v. 5, n. 2, p. 229-234, 2005.

SILVA, G. G.; MENESES, P. P. M. Necessidades de treinamento organizacional e motivação para trabalhar. Revista Eletrônica de Administração, v. 18, n. 1, p. 27-62, 2012.

SOTO, J. A química sustentável: desafios, dilemas e perspectivas. In:
ALMEIDA, F. (Org), Desenvolvimento sustentável 2012-2050: visão, rumos e contradições. Rio de Janeiro: Elsevier, 2012.

TEIXEIRA, A. A.; JABBOUR, C. J. C.; DE SOUSA JABBOUR, A. B. L.; LATAN, H.; DE OLIVEIRA, J. H.C. Green Training and Green Supply Chain Management: Evidence from Brazilian Firms. Journal of Cleaner Production, v. 116, p. 170-176, 2016.

UNNIKRISHNAN, S.; HEGDE, D. S. Environmental training and cleaner production in Indian industry - A microlevel study. Resources, Conservation and Recycling, v. 50, n. 4, p. 427-441, 2007.

VAN KLEEF, J. A. G.; ROOME, N. J. Developing capabilities and competence for sustainable business management as innovation: a research agenda. Journal of Cleaner Production, v. 15, n. 1, p. 38-51, 2007.

YIN, R. Estudo de Caso: Planejamento e Métodos. 4. ed. Porto Alegre: Bookman, 2010 .

WIEK, A.; WITHYCOMBE, L.; REDMAN, C. L. Key competencies in sustainability: a reference framework for academic program development.

Sustainability science, v. 6, n. 2, p. 203218, 2011.

\footnotetext{
${ }^{\mathrm{i}}$ Doctor in Administration concluded in 2017 by the Master's and Doctoral Program in Administration (PMDA) at Universidade Nove de Julho. Thesis title: Environmental Training and the Generation of Competencies for Environmental Sustainability: a study with companies in the Brazilian chemical sector. Master in Administration completed in 2011 by the Master's and Doctoral Program in Administration (PMDA) at Universidade Nove de Julho. Dissertation Title: Learning and Organizational Change. Graduated in Administration. Professor at the Federal Institute of Southern Minas - Campus Carmo de Minas. Interested in research on the themes: Environmental Training, Environmental Management, Strategic People Management, Learning and Organizational Change, Knowledge Management and Practice Communities. Member of the research group on Observational Studies in the Teaching-Learning Process and Research in Administration, at the Federal University of São Paulo.
}

${ }^{\text {ii }}$ Doctor in Administration from the University of São Paulo, FEA USP, 2012. Master in Administration 
from the University of São Paulo, FEA RP USP, 2007. Graduated in Administration from the Federal University of Lavras, UFLA, 2005. She is currently director of the Post-Graduate Program. Degree in Administration from Universidade Nove de Julho, PPGA UNINOVE. She is a research productivity fellow, CNPq-PQ 2, and a professor of Master's and Doctorate courses in Administration, Innovation, Entrepreneurship and Sustainable Business at PPGA UNINOVE. She is Editor-in-Chief of the International Journal of Innovation (IJI) and Associate Editor of the Innovation \& Management Review (IMR). She is the leader of the CNPq Research Group, entitled Innovation Strategy, and within the group she coordinated research projects funded by CNPQ and FAPESP. She has experience in the area of Administration and her main research themes are: company-university cooperation, dynamic capabilities, relational capacity, absorptive capacity and internationalization of innovation.

iii Post-Doctorate in Nuclear Technology at the Institute of Energy and Nuclear Research - Nuclear Fuels Center (2011 - IPEN-CCN/USP). PhD in Materials Science and Engineering from the Federal University of Santa Catarina (UFSC) with a doctoral internship period at the Department of Ceramics and Glass at the University of Aveiro - Portugal (2005). Master in Chemical Engineering from the Federal University of Santa Catarina (2001 - UFSC). Bachelor's Degree in Chemistry (1999) at the Federal University of Santa Catarina (UFSC), Bachelor's Degree in Administration (2018) and in Pedagogical Training for Professional Education Trainers (2007) at the University of Southern Santa Catarina (UNISUL). Productivity Scholarship in Technological Development and Innovative Extension Level 1D - CNPq. Adjunct Professor at the Federal University of São Paulo - Paulista School of Politics, Economics and Business (EPPEN/UNIFESP). She also works as a professor and researcher at University São Judas Tadeu in undergraduate courses and in the Professional Master's Degree in Civil Engineering. Guest researcher at Instituto Ânima Sociesc de Inovação. Collaborating researcher at the Institute for Advanced Studies - IEA/USP Global Cities Program. Researcher at the University of Taubaté (UNITAU). It works in the areas of Project Management, Environmental Management and Sustainability, Technological Innovation, Innovation Management, Technology Management, Operations and Processes, Valorization of Industrial Waste, Smart and Sustainable Cities and Industrial Property (Patents), interacting with interdisciplinary and multidisciplinary groups . Adjunct Editor of the International Journal of Public and Administration Debates - RIDAP and of the Journal of Urban Technology and Sustainability - JUTS. 